\title{
Improving transition between power optimization and power limitation of variable speed, variable pitch wind turbines using Fuzzy control techniques
}

\author{
M.A.M. Prats*, J.M. Carrasco**, E. Galván**, J.A. Sánchez ${ }^{* *}$, L.G.Franquelo** C.Batista*** \\ Dpto. de Física Aplicada e \\ Ingeniería Eléctrica. \\ Escuela Politécnica Superior. \\ Universidad de Huelva. \\ Ctra. de Palos de la Frontera s/n \\ Dpto. de Ingeniería Electrónica \\ Escuela Superior de Ingenieros \\ Universidad de Sevilla \\ Camino de los Descubrimientos s/n \\ 41092 Sevilla \\ MADE Energías Renovables, S.A. \\ Torre Europa. \\ $P^{\circ}$ Castellana 95, planta 29, 28046 \\ Madrid
} 21819 Huelva.

\begin{abstract}
This paper presents an application of fuzzy controllers for improving wind energy capture for variable speed wind turbines. In recent works [1][2][3][4], it has been shown that variable speed wind turbines with torque and blade-pitch linear control provide an excellent performance of the closed loop system. However, this performance can be enhanced by using fuzzy control. In the present work, a computational fuzzy model is presented for a variable speed, variable pitch wind turbine. Simulation results show an excellent performance improving transition between power optimization and power limitation of the wind turbine, specially in the rated wind speed working conditions.
\end{abstract}

\section{Introduction}

Variable speed, horizontal axis grid integration wind turbines using torque and blade-pitch control improve the captured wind energy [1][3]. Maximun power coefficient $\mathrm{Cp}$ and optimum tip-speed-ratio $\lambda$ will be achieved using blade pitch control. The power coefficient $\mathrm{Cp}$ is the ratio between mechanic power and the power captured from the wind. Measures of aerodynamic losses have been considered by this coefficient. Its maximum value is given by Betz's limit (59\%) [3]. The ratio between blade speed and wind speed is the tip-speed-ratio $\lambda$. The tipspeed-ratio is equal to:

$$
\lambda=\frac{\mathrm{wR}}{\mathrm{V}_{\mathrm{W}}}
$$

Where $\mathbf{w}$ is rotor speed, $\mathbf{R}$ is rotor radius and $\mathbf{V}_{w}$ is wind speed.

Variable speed wind turbine provides a better efficiency in partial load range. The mechanical stresses are reduced allowing a certain speed range by temporality storing energy in the rotor.

Wind turbines start to provide power from $3-4 \mathrm{~m} / \mathrm{s}$ wind speed. Maximum power is given for nearly wind speed to $12.5 \mathrm{~m} / \mathrm{s}$. Wind speed higher than $25 \mathrm{~m} / \mathrm{s}$ is recommended to brake wind turbine [5][3].
There are two control methods to limit the captured wind power from 12.5 to $25 \mathrm{~m} / \mathrm{s}$. Stall regulation is a passive control which uses turbulences to decrease power coefficient Cp. This control method provides a smaller power than rated power. There is another kind of control based on blade-pitch control which permit to keep constant the rated power. In this work this second method will be satisfactory used.

It is also important to note that either a conventional PI controller or a fuzzy controller can be used for torque and blade pitch regulation. Proper design of fuzzy controllers makes them superior to traditional linear control techniques. Fuzzy logic provides a means for synthesizing a controller form engineering experiences that can be more robust and have better performance.

Wind turbine can be controlled by two speed controllers. One of this is for blade pitch controlling at high wind speed and the other one is for torque controlling at low wind speed. A nonlinear model of the wind turbine from the inputs is presented. For those kind of systems, classic control it is not sufficient to control them. Because of this, tunning gains in different working conditions is necesary.

Fuzzy control provides a systematic way to incorporate human experience about how to control a nonlinear process. This heuristic approach can improve the performance of the closed loop system [6][7].

Relevant fuzzy logic applications can be found in nonlinear control because a properly designed fuzzy controller can outperform traditional PI and PID controllers. The fuzzy controller's success is based on its ability to simultaneously process several rule implications, thus producing a more complete output.

Fuzzy logic is useful in the frame of control problems when there are not accurate process models and when only qualitative information is available. The application of fuzzy logic makes it possible to find eficient solutions in complicated systems designed from the human experience [8].

\section{Wind turbine model}

In Fig.1., it is shown the block diagram referring to the simplifier mechanical model of a wind turbine. 
The inputs of the wind turbine model are: the wind speed, the blade pitch angle and the torque of the generator. The output is the rotation speed in the high speed shaft and the generated electric power.

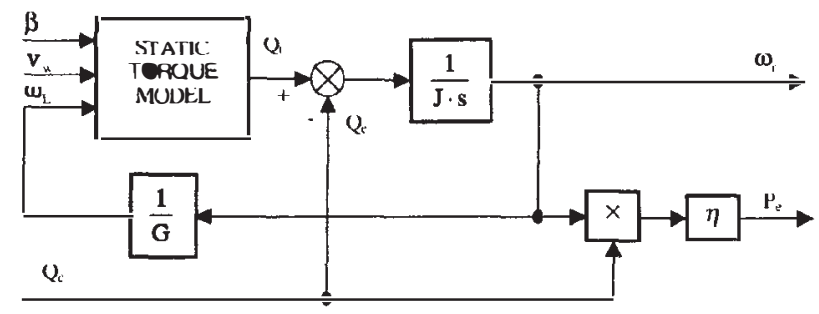

Fig. 1. Mechanical model of the wind turbine

The motor torque is subtract from the load torque of the electric generator $(\mathrm{Qe})$ to obtain the angular shaft speed from the following differential equation (the friction is neglected).

$$
Q_{1}-Q_{e}=J d w_{1} / d t
$$

Static torque model is represented in Fig.2.

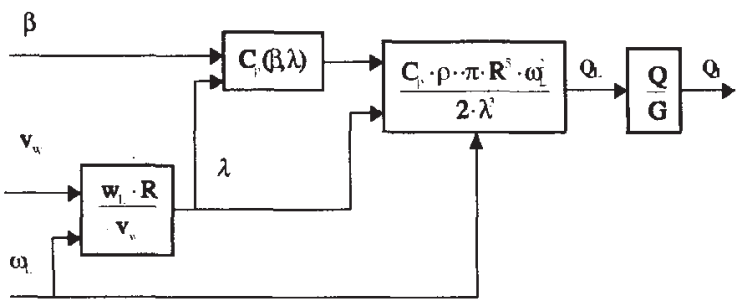

Fig.2 Block for calculating the mechanical torque

Where $\rho$ is the air density, $R$ is the rotor radius, $\beta$ is the blade pitch angle, $\lambda$ is the desired tip speed ratio, $\operatorname{Cp}(\lambda, \beta)$ is the power coefficient and $J$ is the moment of inertia of the turbine rotor.

The torque $Q$, that the wind turbine draws from the wind is equal to the torque in the low speed shaft $Q_{\text {, }}$ divided by the gear box ratio, $G$ :

$$
Q_{1}=Q / G
$$

The function of the gearbox is to adapt the low rotation speed of the rotor axis to the higher one in electric generator.

In this model, the air density, the rotor radius, the gearbox ratio and the moment of inertia in the high speed shaft can be defined.

A frecuency converter decouples the generator from the grid, allowing the rotor speed to vary by controlling the generator reaction torque [3]. This power converter works as a driver, controlling the torque generator by using a vectorial control strategy. Since mechanic response is slower than electric response, the dynamic of the electric generator is not included in the wind turbine model. The electric time constant is negligible compared to mechanic time constant. The designed system is controlled by a torque command. This command is instantaneously transmited to the shaft. It will be the load torque of the wind turbine. The fluctuations produced by mechanic resonances are not included in this model.

Fig.3. shows a diagram block of a power converter for a wind turbine.

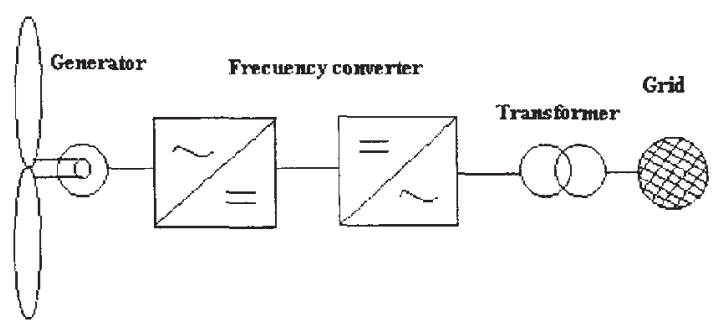

Fig. 3. Frequency converter system for the grid connection of wind power plants

The following equation provides the expression of the aerodynamic torque of the wind turbine.

$$
\mathbf{Q}_{\mathrm{L}}=\rho \mathbf{C p}(\lambda) \pi \mathbf{R}^{5} \mathbf{w}_{\mathrm{L}}{ }^{2} / 2 \lambda^{3}
$$

For steady state operation at tip speed ratio for optimum power coefficient, $\mathrm{Cp}_{0}$, the equation can be reduced to:

$$
\mathrm{Q}_{\mathrm{L}}=\rho \mathbf{C} \mathbf{p}_{0}(\lambda) \pi \mathbf{R}^{5} \mathbf{w}_{\mathrm{L}}{ }^{2} / 2 \lambda_{\mathrm{o}}{ }^{3}=\mathrm{K} \mathrm{w}_{\mathrm{L}}{ }^{2}
$$

This is the torque-speed equation often used for open loop variable speed control of a wind turbine. When the generator torque demand is set to $\mathrm{K} \mathrm{w}_{\mathrm{L}}{ }^{2}$. Where $\mathrm{w}_{\mathrm{L}}$ is the measured generator speed. This ensures that in the steady state the turbine will work with an optimum tip speed ratio and the corresponding maximum power coefficient.

In this case, a close loop controller has been used where Wref is obtained from equation (5) and the block diagram is shown in Fig.4.

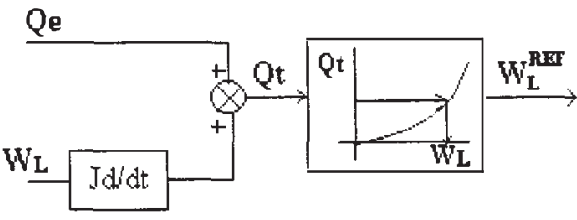

Fig.4. Estimated Wref model 
If pitch angle control is used in the system along with variable speed, better performance is obtained. For instance, to permit the starting blade pitch angle to differ from the operation blade pitch angle, hence allowing easier starting and optimum performance. Moreover, the power and speed can be limited through rotor pitch regulation.

At low winds it is possible to maximise energy capture following a constant tip speed ratio load line which corresponds to operation at the maximum power coefficient. This load line is a quadratic curve in the torque speed plane as it is shown in Fig.5. During that time, the pitch angle is adjusted to a constant value, the maximum power pitch angle. At very low wind speed it is not possible to follow this curve because there is a minimum allowed operating speed. Then the wind turbine is operated at a constant speed Wmin. At high wind speed it is necesary to limit the torque $Q_{n}$ or power Pn of the generator to a constant value.

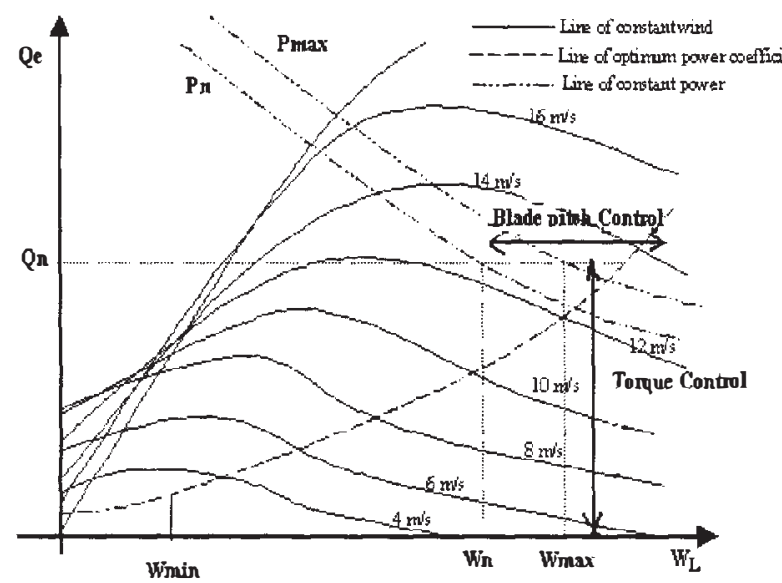

Fig.5. Variable sneed nitch regulated onerating curve

\section{Fuzzy controller design for the wind turbine}

Shown in Fig.6. is a block diagram of a fuzzy controlller which includes a fuzzification block, a knowledge base, a fuzzy inference engine and a defuzzification block.

The fuzzy process maps a crisp point of real meaning such as measured data, into fuzzy sets, by the knowledge of the input membership functions. The fuzzy inference engine then uses the rules in the rule base to produce fuzzy sets at its output, corresponding to its input fuzzy sets. The fuzzification process employed the knowledge of the output membership functions to map the output fuzzy sets into a crisp value that is usable [9]. Centroid defuzzification has been used in the fuzzy controllers design. The knowledge base of the fuzzy system stores the expert knowledge on how to control the wind turbine. All the inputs and the outputs are nomalized with tuning.

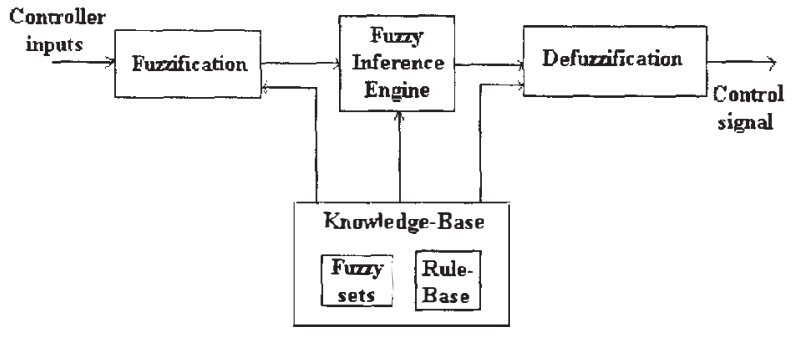

Fig. 6. Fuzzy System Structure

The membership function defining the fuzzy values of controller inputs and controller outputs are defined offline, on a common normalized domain. This normalization is done by the normalization factors. The gains Kin1, Kin2, Kin3, Kin4, Kout1 and Kout2 in Tabla.I. were employed to normalize the universes of discourse. The universes of discourse for each input are nomalized to the interval $[-1+1]$ by means of constant scaling factors. These gains can be varied to tune the fuzzy controller for a desired performance.

\begin{tabular}{|c|c|c|c|c|c|}
\hline Kin1 & Kin2 & Kin3 & Kin4 & Kout1 & Kout2 \\
\hline $3.15 \mathrm{e}-3$ & $2.58 \mathrm{e}-3$ & $3.03 \mathrm{e}-4$ & $8.39 \mathrm{e}-5$ & $1.00 \mathrm{e} 2$ & $1.00 \mathrm{e} 5$ \\
\hline
\end{tabular}

Table I. Normalisation factors

Standard triangular membership functions have been used for both the input fuzzy sets and the outputs fuzzy sets of the fuzzy controllers. The designed fuzzy sets are shown in Fig. 7. and Fig.8.

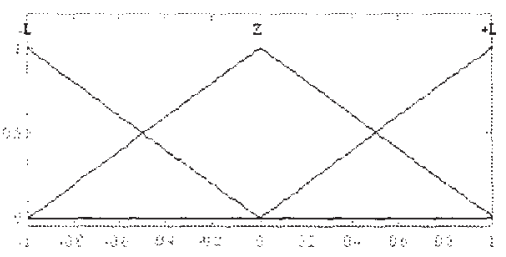

Fig. 7. Triangular Membership Functions for input fuzzy sets on a universe of discourse.

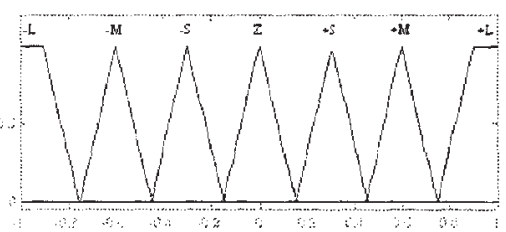

Fig. 8. Triangular Membership Functions for output fuzzy sets on a universe of discourse. 
The control law of a fuzzy controller is represented by a set of heuristically chosen fuzzy rules. The designed fuzzy rules used in this work are given in Table.I.

$$
\text { error }
$$

\begin{tabular}{cc|c|c|c|} 
& & \multicolumn{1}{|c}{$-\mathrm{L}$} & $\mathrm{Z}$ & $+\mathrm{L}$ \\
\cline { 2 - 5 } integral & $-\mathrm{L}$ & $-\mathrm{L}$ & $-\mathrm{S}$ & $+\mathrm{S}$ \\
\cline { 3 - 5 } error & $\mathrm{Z}$ & $-\mathrm{M}$ & $\mathrm{Z}$ & $+\mathrm{M}$ \\
\cline { 3 - 5 } & $+\mathrm{L}$ & $-\mathrm{S}$ & $+\mathrm{S}$ & $+\mathrm{L}$ \\
\cline { 3 - 5 } & & & &
\end{tabular}

Table II. Fuzzy controller Rule Base

\subsection{Fuazy torque controller}

The developed control system has integrated a fuzzy controller for torque control of the generator that can improve the captured energy at low wind speeds.

The block employed for torque control of the generator provides the torque command of the electric generator. Its input is the speed error . The speed error and integral speed error are scaled. This speed error is obtained from Wref (Fig.4.), and $W_{L}$ (this is the measured generator speed). The output is the reference torque.

\subsection{Fuzzy pitch controller}

The other fuzzy system has been designed for blade

The following fuzzy sets have been defined. - $L$ is small, $Z$ is zero, $+S$ is positive small, $+M$ is positive

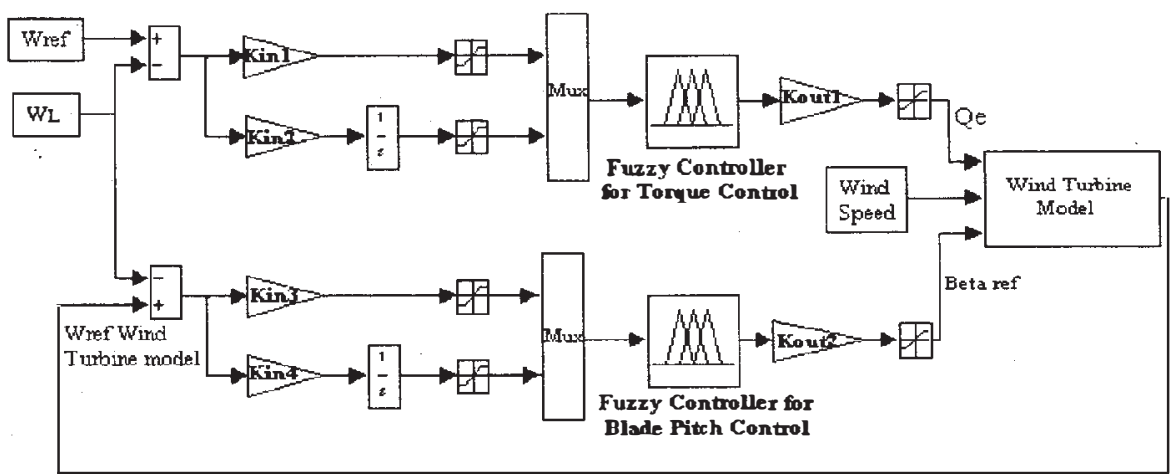

Fig.10. Block diagram of the fuzzy controllers

medium and $+\mathrm{L}$ is positive large.

Given the rules and membership functions, the fuzzy controller produces the crisp and continuous nonlinear input/output (VO) map.

The fuzzy map indicates that numerous nonlinearities are designed to enhance the controllers ability to drive the system to the set point. Note that near the center of the map, the surface in Fig.9. appears to be smoth. Which means that for a small operating range the fuzzy controller behaves like a linear controller. Soft and nonlinear control actions resulted from the fuzzy rules can improve the wind turbine performance.

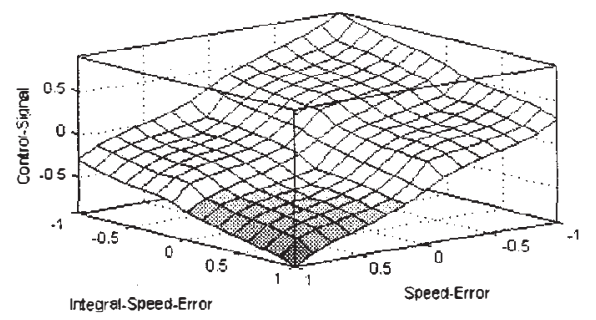

Fig.9. Fuzzy Controller Nonlinear Input/ Output Map pitch control. The inputs of this one are: the speed error and integral speed error. If $\mathrm{W}_{\mathrm{L}}$ is subtracted to Wref, this speed error can be obtained. The controller output is the reference pitch angle $\beta$ ref.

The block diagram showing the implementation of the fuzzy controllers is illustred in Fig.10.

\section{Simulation results}

The considered $600 \mathrm{KW}$ wind turbine is equipped with a three blade and blade pitch control. Its parameters are shown in table III. Where $J$ and $Q n$ are refered to the high speed shaft.

\begin{tabular}{|c|c|c|c|c|}
\hline $\mathbf{J}\left(\mathbf{K g} \cdot \mathbf{m}^{2}\right)$ & $\mathbf{R}(\mathbf{m})$ & $\mathbf{Q n}(\mathbf{N m})$ & $\mathbf{P n}(\mathbf{K w})$ & $\mathbf{G}$ \\
\hline 136.27 & 20.5 & 3820 & $\mathbf{4 0 0}$ & $\mathbf{4 7 . 4 4}$ \\
\hline
\end{tabular}

Table III. Parameters of the simulated wind turbine

Advantages of the fuzzy controllers over conventional linear controllers include nonlinear control actions and less dependence on mathematical models. Fuzzy controllers can also better reject against the noise, disturbances and parameters variations.

In this work, the fuzzy control strategy as well as allows to extract a small improvement in energy capture in low and high wind speed, they can also enhance 
performance in the transition between power optimization and power limitation in rated wind speed. This model has been implemented with MATLAB (Simulink) software and its scheme is shown in Fig. 11.
Fig.13 -16 show a improvement in energy capture and speed control in the transition between power optimization and power limitation in rated wind speed.

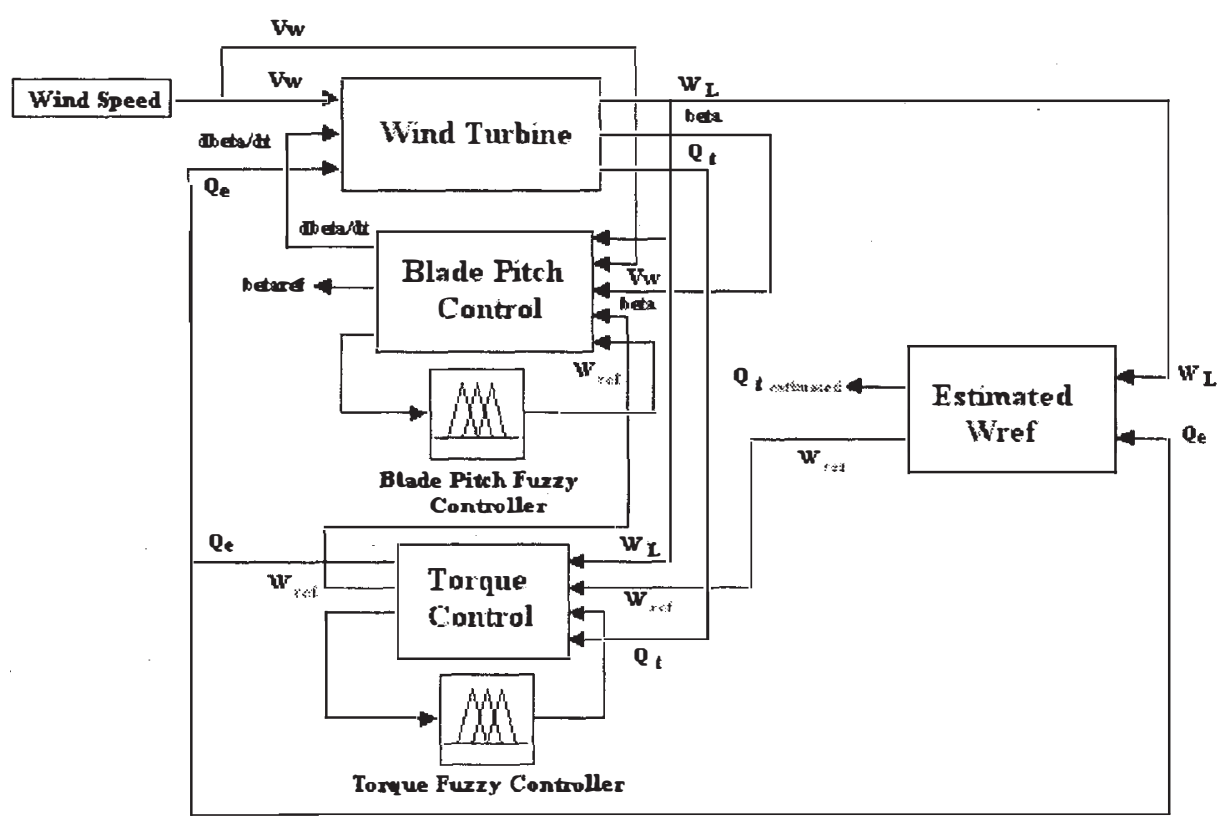

Fig.11. Block diagram of the simulated system in this work.

The wind turbine operation is simulated in the time domain (s). The simulation time used is $400 \mathrm{~s}$. The rated wind speed time series used in the simulation are shown in Fig.12

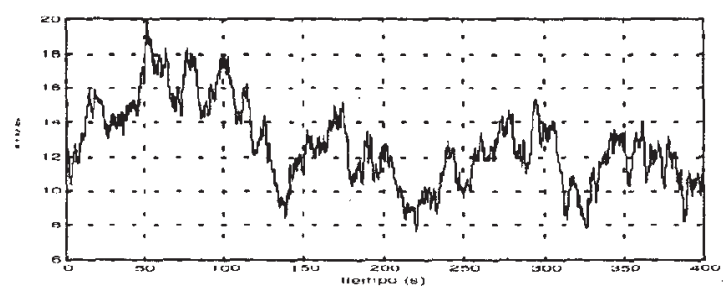

Fig.12. Rated wind ( $12 \mathrm{~m} / \mathrm{s}$ average value)

Simulations from these different wind speed inputs cases show better results for the fuzzy control system if it is compared with the linear control system. It is used for improving wind energy capture.

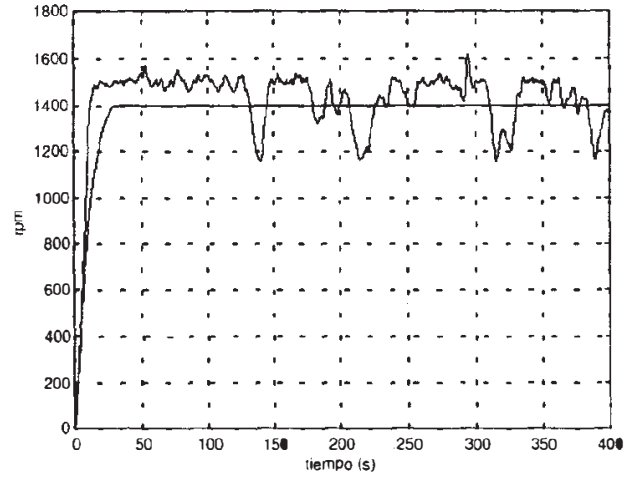

Fig.13. Rotor speed for the rated wind time series of the PI Control System

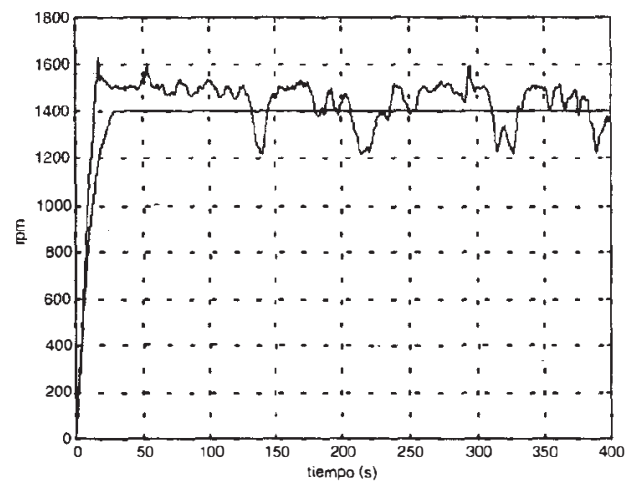

Fig.14. Rotor speed for the rated wind time series of the Fuzzy Control System 


\section{Power of the PI Control System}

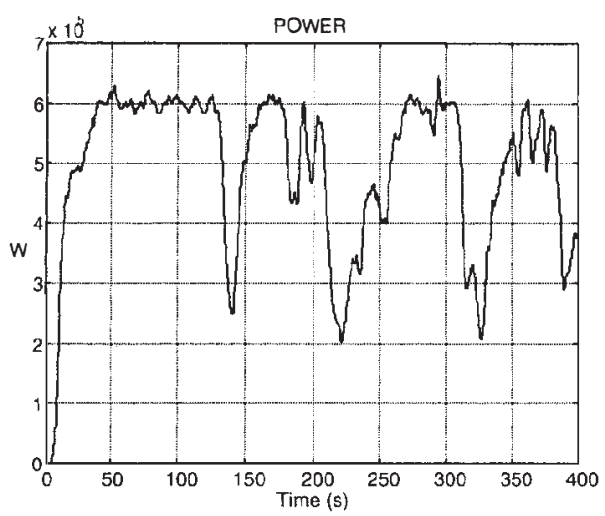

Fig.15. Generator Power for the rated wind time series of the PI Control System

\section{Power of the Fuzzy Control System}

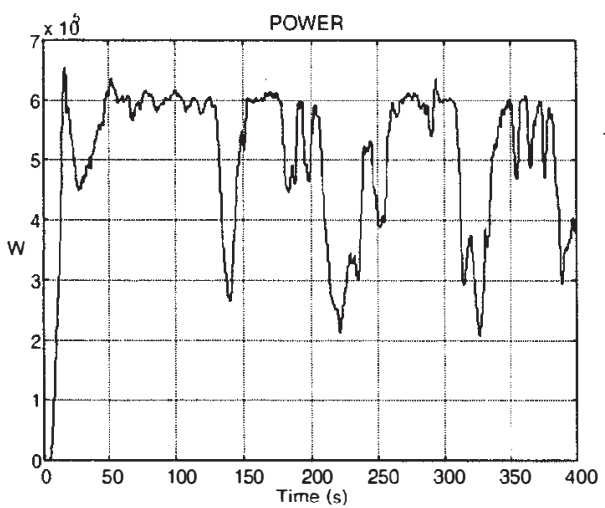

Fig.16. Generator Power for the rated wind time series of the Fuzzy Control System

Simulation results in rated wind speed conditions (12 $\mathrm{m} / \mathrm{s}$ mean value) are shown in table IV.

\begin{tabular}{|c|c|c|}
\hline & PI & Fuzzy \\
\hline Energy (kWb) & 54.658 & 55.703 \\
\hline Max. Rotor speed (m/s) & 1618 & 1630 \\
\hline $\mathbf{Q}_{\text {maximun! }}(\mathbf{N m})$ & 3820 & 3820 \\
\hline $\mathrm{T}_{\text {arcrage }}(\mathbf{N m})$ & 3238 & 3287 \\
\hline $\mathrm{T}_{\text {rms }}(\mathbf{N m})$ & 768 & 740 \\
\hline
\end{tabular}

Table IV. Simulation results in rated wind spead $(12 \mathrm{~m} / \mathrm{s}$ average value)
Fuzzy controllers over conventional linear controllers present better speed control and blade pitch control at low and high wind. Improving of captured energy is obtained at rated wind

\section{Conclusions}

In this work, a fuzzy logic application has been developed for improving captured energy for variable speed and blade pitch wind turbine.

This paper presents a dynamic model of a variable speed wind turbine using torque and blade-pitch fuzzy control. Simulation results show the robustness of the fuzzy controllers. Soft and nonlinear control actions of these controllers can improve the wind turbine performance at low, rated and high wind speed. The proposed control scheme improves the transition between power optimization and power limitation of the wind turbine. Torque fuzzy control at low rotor speed (low wind speed) and blade pitch fuzzy control at high rotor speed (high wind speed) have been used in the designed model.

Results compare very favourably with those obtained by using linear controller.

\section{References}

[1] K. Pierce. "Control Method for Improved Energy Capture below Rated Power". $3^{\prime 3}$ ASMEJSME Joint Fluids Engineering Conference, San Francisco, Califomia, 1999.

[2] O. Carlson, J. Hylander, K. Thorborg. "Survey of variable speed operation of wind turbines". EIJWEC'96, Göteborg, Sweden, 1996.

[3] Siegfried Heier. "Grid Integration of Wind Energy Conversion Systems". John Wiley \& Sons, 1998.

[4] M. Maureen Hand, Mark J. Balas. "Non linear and linear model based controller design for variable - speed wind turbines". $3^{\text {rit }}$ ASMEJSME Joint Fluids Engineering Conference, San Francisco, California, 1999.

[5] E. Muljadi, K. Pierce, P. Migliore. "Control Strategy for Variable - Speed, Stall - Regulated Wind Turbines". American Controls Conference Philadelphia, 1998.

[6] Whadyslaw Mielczarski. "Fuzzy Logic Techniques in Power Systems". Physica - Verlag, 1998.

[7] Rainer Palm, Dimiter Driankov, Hans Hellendoon. "Model Based Fuzzy Control". Springer, 1997.

[8] K. Hirota. "Industrial Applications of Puzzy Technology". Physica - Verlag, 1993.

[9] Yifan Tang, Longya Xu. "Puzcy Logic Application for Intelligent Control of a Variable Speed Drive".IERE Transactions on Energy Conversion, Vol.9, No. 4, December 1994. 